International Journal of Engineering \& Technology, $7(3.17)(2018) 5-14$
International Journal of Engineering \& Technology
SPC
Website: www.sciencepubco.com/index.php/IJET
Research paper

\title{
CFD Simulation of Automotive Pollutant Dispersion in High-Rise Building Urban Environment Under Deeply Stable Atmospheric Condition
}

\author{
E. R. Lotfy ${ }^{1,3}$, W. M. F. Wan Mahmood ${ }^{1,2}$, R. Zulkifli ${ }^{1,2}$ and Z. Harun ${ }^{1,2^{*}}$ \\ ${ }^{I}$ Centre for Integrated Design for Advanced Mechanical Systems (PRISMA) \\ Faculty of Engineering and Built Environment \\ Universiti Kebangsaan Malaysia, 43600, Bangi, Malaysia \\ ${ }^{3}$ Department of Mechanical Engineering, Alexandria University \\ 21544 Alexandria, Egypt \\ *Corresponding author E-mail: zambri@ukm.edu.my
}

\begin{abstract}
The layer of atmosphere adjacent to the earth's surface which is affected by friction, heat transfer and pollution from the surface is called the atmospheric boundary layer (ABL). At nighttime, the earth's surface becomes colder than the upper atmospheric layers. The thermal stratification with heavy cold layers close to the ground and light hot ones upwards dampens mixing currents in the atmosphere; a condition named as stable ABL. The absence of mixing at night causes the pollutants released from ground sources, such as automotive transportation, to settle in the layers close to the earth which affects human health. This research is a CFD investigation of the effect of building density on pollutant dispersion in urban areas under severe atmospheric stability condition. Three plane area densities were examined 35, 25 and 15\%. Carbon dioxide was considered as the pollutant. Large eddy simulation (LES) was utilized in the simulation. The results have proven the positive effect of building structures in dispersing pollutants. However, high building densities above $25 \%$ trap high concentrations of pollutants at the pedestrian level. The research may offer recommendations for the city planners and legislators about traffic pollution and architectural planning.
\end{abstract}

Keywords: Air flow; atmospheric boundary layer; CFD; traffic pollution; urban environment.

\section{Introduction}

The study of atmospheric flow near buildings is important to mankind. There are many reasons for this, urban heat island issues (UHI) is one important aspect. The denser are the buildings in a given footprint, the harder it is for fresh air to go through the city to remove heat and pollution. Subsequently, harmful gases produced by anthropogenic sources, e.g. automobiles, can concentrate around buildings at the pedestrian level. Research by the US-based Health Effects Institute (HEI) showed that air pollution caused more than 4.2 million early deaths worldwide in 2015 , making it the fifth highest cause of death, with around 2.2 million deaths in China and India alone [1]. The atmospheric boundary layer (ABL) is a term defining such bottom layer of atmosphere where the flow properties, e.g. velocity, temperature and chemical composition, are affected by interaction (friction, heat transfer and pollutant dispersion) with the earth's surface $[2,3]$. Depending on the surface conditions, the ABL can extend up to tens or hundreds of meters. During daylight hours the earth's surface is hotter than the atmosphere, thanks to the solar radiation, and hence the adjacent air layers are hotter than the further ones. The temperature difference causes the density structure of the atmosphere to be unstable. As a result, vortical buoyant motions devel- op. This vortical motions compose the main engine for mixing atmospheric layers and dispersing ground-source pollutants. The $\mathrm{ABL}$ height expands to $1-2 \mathrm{~km}$. In contrast, at night time, the earth's surface loses its temperature by radiation to space and becomes colder than the atmosphere. Hence the new density structure is stable. The stable thermal stratification not only lacks buoyant overturning currents but also suppresses the mechanical friciton turbulence. Thus the ABL height shrinks to only few tens of meters. For an urban area with many anthropogenic pollution sources a long-lasting stable ABL can be fetal due to the absence of layer stirring and pollutant dilution [4].

Many authors performed field measurements, wind tunnel model experimentation or CFD simulations for the wind flow through urban areas to determine the effect of building design and $\mathrm{ABL}$ stability condition on heat dissipation and pollutant dispersion. From there, large eddy simulation (LES) of the atmospheric flow in the DAPPLE site, London, Xie and Castro [5] discovered that the scalar dispersion is affected by the source location only in the near field. Whereas, far from the source, the source location is of minor impact. This was confirmed by Gousseau, et al. [6] who held a wind-tunnel-validated CFD simulation of the flow in downtown Montreal. They displayed also the proper simulation 
of the flow separation at the building edges to be crucial for predicting the concentration field.

The wind flow through downtown Macao was simulated by Liu et al. [7] under realistic wind speed and temperature conditions. The results have shown the importance of the buoyancy effect on turbulence intensity and hence pollutant dispersion. The residence time of a gas in the wake of a building, consequently, is longer for stable rather than unstable states [8]. The air exchange in urban areas is driven by the buoyancy effect under unstable condition and flow turbulence under neutral condition [9]. This is in contrary to Hang et al. results [10] who studied the particle dispersion in high-rise building arrays with variable-heights and found the mean flow to be more important than turbulent diffusion. The pedestrian flow and contaminant gas concentration depend on the approach wind structure even in condensed urban areas [11]. The three dimensional nature of the flow structure around buildings drives the concentration field to be three dimensional as well [12].

The increase in the numbers of skyscrapers in modern urban areas such as Kuala Lumpur City Centre (KLCC) negatively affects the pollutant dispersion. The denser the built area is, the less the space available for ventilation is and the more the pollution sources are. It is very timely to study the pollution dispersion from traffic sources in such modern urban environments. The main objective of this study is to detect the effect of building packing density on the pollutant concentration map. The case study is KLCC under a deeply stable atmospheric condition. This is expected to provide a guideline for city council and planners.

\section{Method}

Computational fluid dynamics (CFD) is an accredited tool for atmospheric flow simulation if the proper setting of the computational parameters is granted [12]. Thanks to its ability to capture turbulence properties, LES has got a wide popularity as a CFD tool to predict the flow field and concentration distribution in urban environments e.g. $[6,13,14]$.

\subsection{Mathematical Model}

In the LES a filtration function is applied to the governing equations so that all eddies larger than the grid size are explicitly resolved (simulated) while the smaller eddies are modeled using so-called subgrid-scale (SGS) models. The filtered continuity, momentum, energy and concentration equations are listed below:

$$
\begin{aligned}
& \frac{\partial \rho}{\partial t}+\frac{\partial}{\partial x_{i}}\left(\rho u_{i}\right)=0 \\
& \frac{\partial}{\partial t}\left(\rho u_{i}\right)+\frac{\partial}{\partial x_{j}}\left(\rho u_{j} u_{i}\right) \\
& =-\frac{\partial p}{\partial x_{i}}+\rho g_{i}+\frac{\partial}{\partial x_{j}}\left(\tau_{j j}+\tau_{S G S}\right) \\
& \frac{\partial}{\partial t}(\rho h)+\frac{\partial}{\partial x_{j}}\left(\rho u_{j} h\right)=\frac{D p}{D t}+\frac{\partial}{\partial x_{j}}\left[\left(\frac{\mu}{P r}+\frac{\mu_{S G S}}{P r_{t}}\right) \frac{\partial h}{\partial x_{i}}\right] \\
& \frac{\partial}{\partial t}(\rho C)+\frac{\partial}{\partial x_{j}}\left(\rho u_{j} C\right)=\frac{\partial}{\partial x_{j}}\left[\left(\frac{\mu}{S c}+\frac{\mu_{S G S}}{S c_{t}}\right) \frac{\partial C}{\partial x_{i}}\right]
\end{aligned}
$$

Where, $\rho$ is the resolved scale density (the tildas $\sim$ were removed for simplicity), $p$ is the resolved scale pressure, $u_{i}$ is the resolved scale velocity component in the $x_{i}$ direction, $g_{i}$ is the gravitational acceleration component, $h$ is the resolved scale enthalpy $\left(h=c_{v} T+p=\rho\right)$ and $C$ is the resolved scale pollutant concentration. $T$ is the resolved scale temperature and $c_{v}$ is the fluid specific heat at constant volume. $\tau_{j j}$ is the molecular viscosity stress tensor defined as: $\tau_{j j}=\mu\left[\left(\frac{\partial u_{i}}{\partial x_{j}}+\frac{\partial u_{j}}{\partial x_{i}}\right)-\frac{2}{3} \frac{\partial u_{k}}{\partial x_{k}} \delta_{i j}\right]$

$\mu$ and $\mu_{S G S}$ are the fluid molecular and SGS turbulent viscosities. $P r, P r_{t}, S c$ and $S c_{t}$ are the Prandtl (=0.707), turbulent Prandtl $(=1.0)$, Schmidt $(=1.14)$ and turbulent Schmidt $(=0.7)$ numbers. $\tau_{S G S}$ and $\mu_{S G S}$ are calculated using the SGS model, the one equation eddy viscosity model [15] in our case. In this research air was considered compressible [16] and its density was defined by the ideal gas law:

$\rho=\frac{p}{R T}$

\subsection{Geometrical Model, Domain and Mesh}

Special care was given to the model dimensions to design a more realistic model. KLCC, as a case study, is distinguished with its high-rise buildings that can go up to $630 \mathrm{~m}$, Merdeka PNB118 (underconstruction). Nevertheless, they are largely separated with, streets, gardens and low-rise buildings. The average building height-to-length ratio in KLCC was calculated and found to be 2.0. While the plane area density was $\sim 22 \%$. The simulated model comprises an infinite array of equal-height, high-rise, square, in-line arranged and equally spaced buildings, Figure-1. The building height was set to $\mathrm{H}=100 \mathrm{~m}$ and the aspect ratio, height to width, to 2.0. The plane area density, $\lambda p$, is defined as the ratio between the plane area occupied by buildings and the total plane area $\left(\lambda_{p}=A_{\text {Buildings }} / A_{\text {Total }}\right)$. Three plane area densities were examined; 35\% (Figure-1(a)), 25\% (Figure-1(b)) and $15 \%$ (Figure-1(c)). It has to be stressed that inspiring the geometrical features from KLCC doesnot imply that the results of this study strictly apply to KLCC. This is inasmuch as the height variability in the real city is expected to alter the flow structure and dispersion characteristics [17]. However, the current analysis provides rough estimation of the pollutant concentration in typical modern high-rise building cities.

The inlet, outlet and lateral boundaries were assigned periodic conditions. This allows confining the flow domain to one repeating unit of the building network (Figure-1). The height of the domain was set according to the COST action [18-20] namely $5 \mathrm{H}$. The building model was constructed using Autodesk ${ }^{\circledR}$ 123D Design ${ }^{\circledR}$ and exported to a stereolithography STL (file that can readily be read by OpenFOAM, the CFD software employed).

The mesh was divided vertically into two sections. The first section covers the bottom $150 \mathrm{~m}$ of the domain and contains $44 \%$ of the cells. In this section, the cell sizes are not equal but expand gradually at an overall ratio, last cell to first cell sizes, of $\sim 4$. While in the second section of the mesh, $350 \mathrm{~m}$ height and $56 \%$ of the cells, the cell size is uniform. An illustration of the mesh and the boundaries is shown in Figure-3(a) and (b), respectively. Three meshes were examined to ensure the grid-independence of the results; Coarse (C), Medium (M) and Fine (F). The total nominal number of cells in these meshes was $1,1.5$ and 2 million(s) of cells. The specs of the three meshes are detailed in Table-1. The mesh sizes were based on a literature survey for similar cases of urban atmospheric flow. A summary of some recent cases is listed in Table-2. The grid-dependence analysis was held only for, $\lambda_{\mathrm{p}}=25 \%$, and considered the pollutant concentration at four points (P1-P4), Figure-1(b), as a criterion. Although it is impossible to achieve a perfect grid-independent solution via LES $[21,22]$, the grid-dependence analysis has proven the fidelity of the meshes used. Figure- 2 compares the non-dimensional concentration coefficient for the three meshes at the points (P1-P4). The non-dimensional concentration coefficient, $F_{C}$ is defined as:

$F_{C}=\frac{C-C_{\infty}}{C_{0}-C_{\infty}}$ 
Where, $C_{\infty}$ and $C_{0}$ are the freestream and ground level pollutant concentrations. The precision of the $\mathrm{M}$ mesh was found accepta-

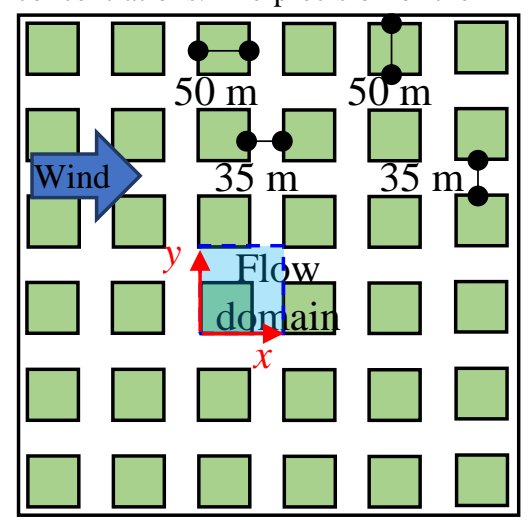

(a) $\lambda_{p}=35 \%$

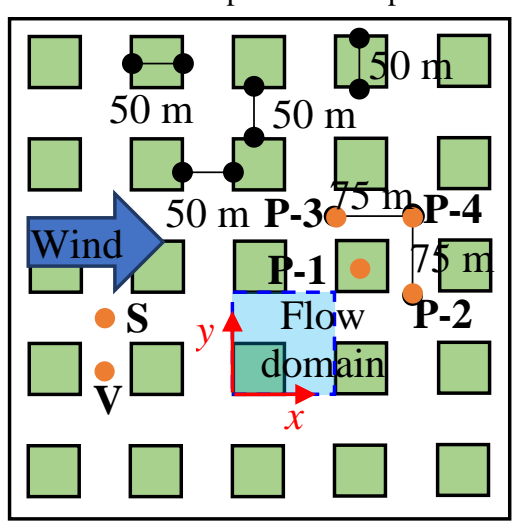

(b) $\lambda_{\mathrm{p}}=25 \%$ ble for this study and hence it will be considered in the pollutant dispersion

Figure-1. The geometrical models implemented in the simulation.

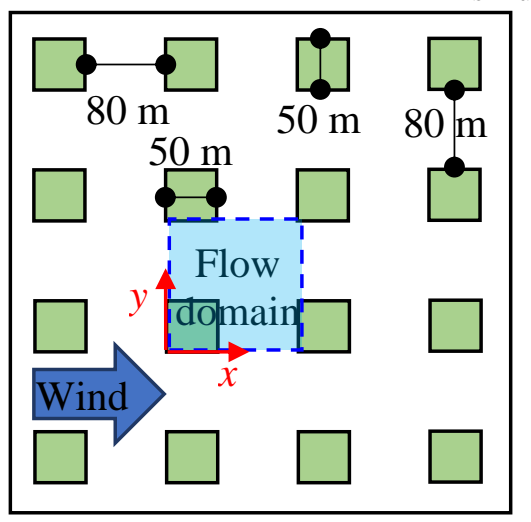

(c) $\lambda_{\mathrm{p}}=15 \%$

Table-1. The details of the three meshes compared.

\begin{tabular}{|c|c|c|c|}
\hline & Coarse (C) & Medium (M) & Fine $(\mathbf{F})$ \\
\hline Mesh size $(\mathrm{Nx} \times \mathrm{Ny} \times \mathrm{Nz})$ & $67 \times 67 \times 226$ & $78 \times 78 \times 247$ & $84 \times 84 \times 284$ \\
\hline Cell size at building surface $[\mathrm{m}]$ & $\begin{array}{c}0.7-1.3 \\
(0.007-0.013 \mathrm{H})\end{array}$ & $\begin{array}{c}0.064-1.2 \\
(0.0064-0.012 \mathrm{H})\end{array}$ & $\begin{array}{c}0.56-1 \\
(0.0056-0.01 \mathrm{H})\end{array}$ \\
\hline Overall expansion ratio in bottom mesh section & 4.04 & 3.98 & 3.93 \\
\hline
\end{tabular}

Table-2. Summary of mesh details for some recent LES computations of atmospheric flow through urban areas.

\begin{tabular}{|c|c|c|c|c|c|}
\hline Reference & Geometry & $\begin{array}{c}\begin{array}{c}\text { Buoyancy includ- } \\
\text { ed }\end{array} \\
\end{array}$ & $\begin{array}{c}\begin{array}{c}\text { Pollutant dispersion includ- } \\
\text { ed }\end{array} \\
\end{array}$ & $\begin{array}{c}\text { Number of grids (mil- } \\
\text { lion) }\end{array}$ & Cell sizes \\
\hline [9] & 2D array of street canyons (13 buildings) & No & No & $2.2-2.5$ & $0.02-0.2 \mathrm{H}$ \\
\hline [5] & DAPPLER site, London & No & Yes & N/A & $0.05 \mathrm{H} \mathrm{ABS*}$ \\
\hline [6] & Downtown Montreal ( $>10$ buildings) & No & Yes & $3-6.5$ & $1.5-3.8 \mathrm{~m}$ \\
\hline [7] & Downtown Macao, China & Yes & Yes & 3 & $0.1 \mathrm{H} \mathrm{ABS}^{*}$ \\
\hline [13] & Street canyon (two buildings) & No & No & 1.1 & $\begin{array}{l}0.077 \mathrm{H} \\
\mathrm{ABS}^{*}\end{array}$ \\
\hline [23] & $\begin{array}{l}\text { Street canyon (two buildings) with tree plant- } \\
\text { ing }\end{array}$ & No & No & 1.2 & $\begin{array}{l}0.077 \mathrm{H} \\
\text { ABS* }\end{array}$ \\
\hline [14] & 2D array of street canyons ( 4 buildings) & No & Yes & 5.2 & $0.02 \mathrm{H} \mathrm{ABS}^{*}$ \\
\hline$[22]$ & One building & No & No & 0.2 & $\mathrm{H} / 32-\mathrm{H} / 8$ \\
\hline [24] & Array of 6 buildings & Yes & No & 0.25 & $0.1 \mathrm{H} \mathrm{ABS}^{*}$ \\
\hline [16] & Building complex ( 7 buildings) & No & No & 3 & $<1 \mathrm{~m} \mathrm{ABS}^{*}$ \\
\hline
\end{tabular}

* ABS: At building surface

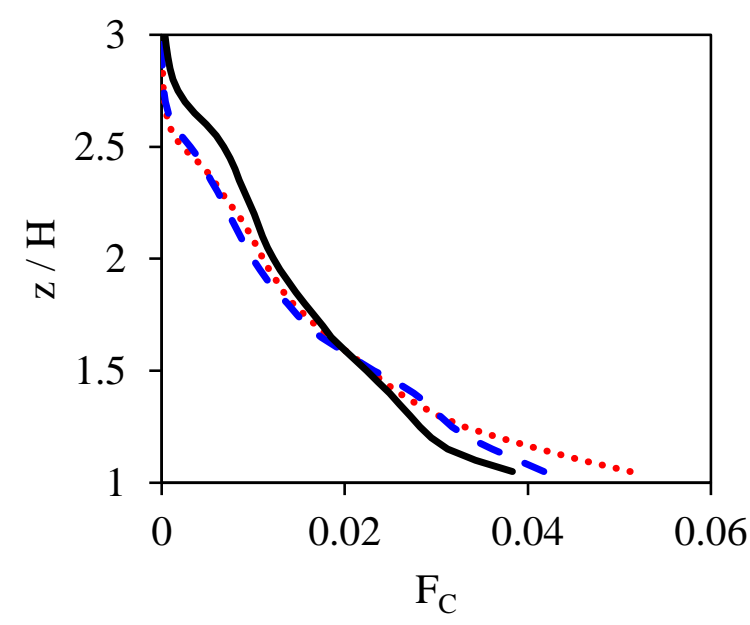

P1

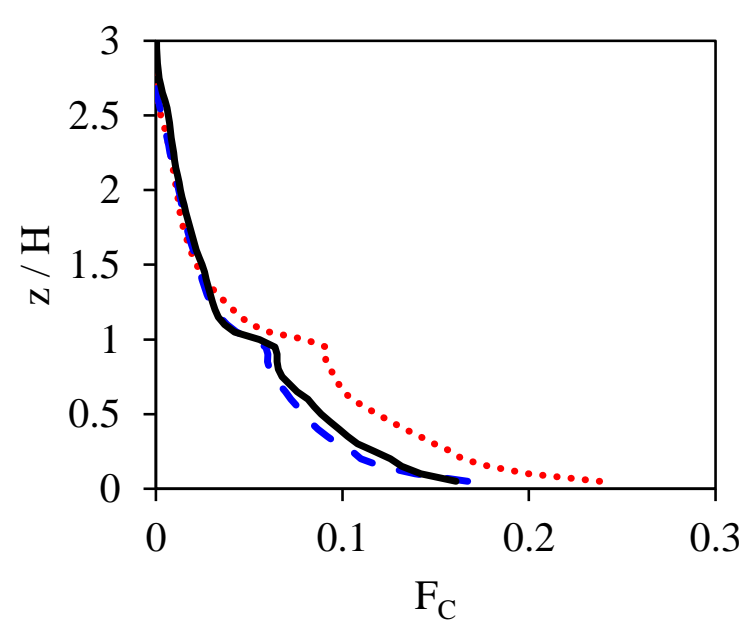

$\mathrm{P} 2$ 


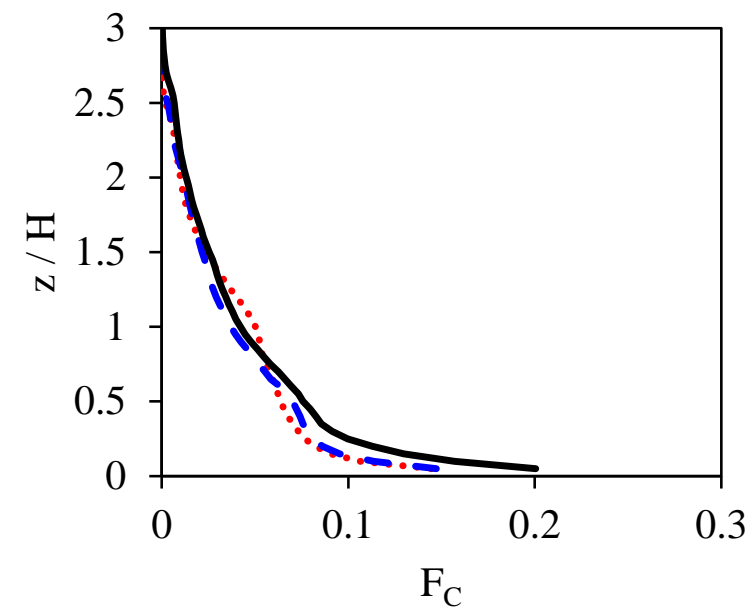

$\mathrm{P} 3$

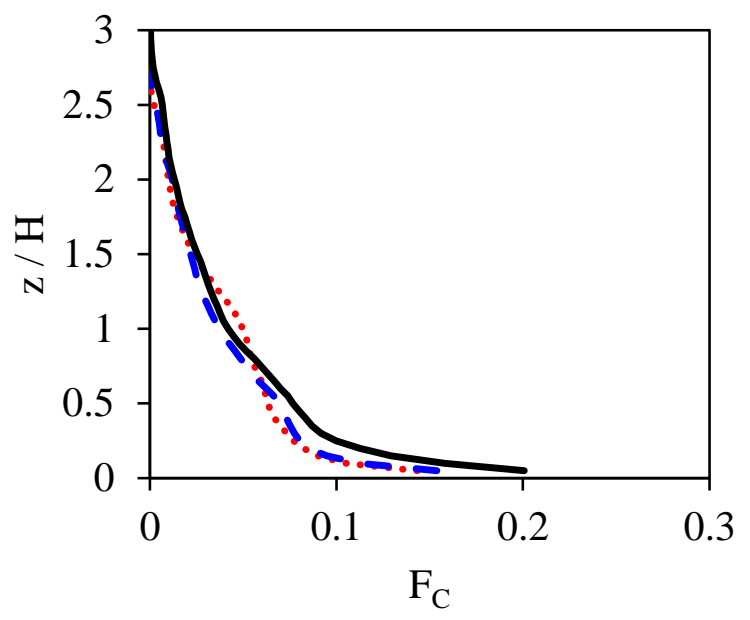

P4

Figure-2. Grid-dependence analysis for the meshes considered; solid line: F mesh, dashed line: M mesh and dotted line: $\mathrm{C}$ mesh.

\subsection{Boundary Conditions}

As mentioned earlier, the inlet, outlet and lateral boundaries were assigned periodic conditions [14,16,17,22,25-27] i.e. the outlet flow properties from one iteration is fed to the inlet in the next iteration. The flow, then, needs to be forced by an external effect e.g. fixed free stream velocity at the top boundary [22]. The cells near the walls, ground and building surface, were assigned standard wall functions to calculate all the turbulent parameters. Although this is not the case in KLCC, the surfaces of the ground and buildings were treated as smooth surfaces to allow refining

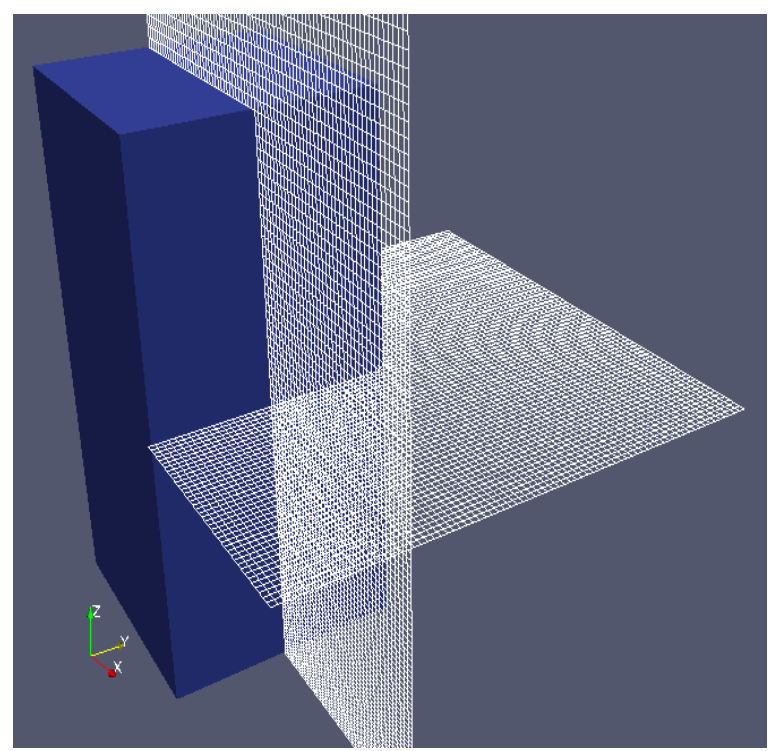

(a) Mesh

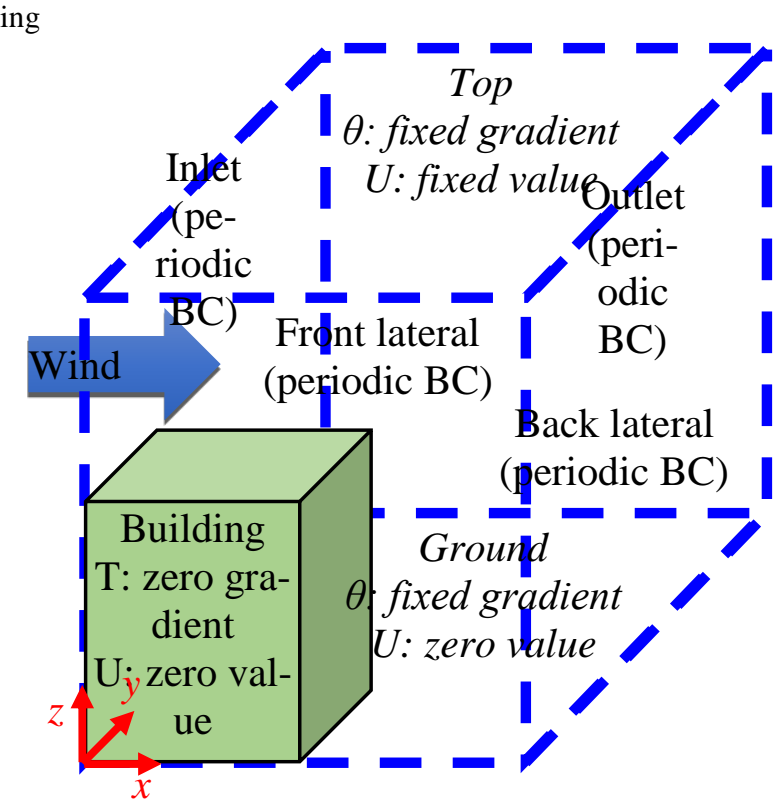

(b) Boundaries

Figure-3. Illustration of the mesh and boundary conditions.

\subsection{Numerical Aspects}

The flow simulations were held by OpenFOAM®. OpenFOAM can realize geometries in the STL format and construct the mesh using the snappyHexMesh tool. Although there are no solvers in OpenFOAM to solve the mass transport equation simultaneously with the momentum and heat transfer equations, one solver can be created by the user since OpenFOAM is an open-source CFD package. The implemented solver was a variant of the standard buoyantPimpleFoam solver. The time step was left adjustable such that the Courant number is less than unity and the solution is stable. The simulation continued for 450 turnovers i.e. the flow sweeps the domain at the free stream velocity 450 times. The the grid size near the walls $[16,19]$. To produce a stable atmospheric condition both the ground and top boundaries were assigned a positive potential temperature gradient. Whereas fixed concentration values representing the traffic sources and free atmosphere were set to the ground and top boundaries, respectively. The buildings were assumed to be thermally insulated and impermeable for mass transport i.e. zero-gradient temperature and concentration conditions were assigned at their surfaces. The boundary conditions are summarized in Figure-3(b). 
Table-3. Flow conditions at the case study selected from the EKOMAR data.

\begin{tabular}{|c|c|}
\hline & Value \\
\hline Free stream velocity, $U_{\infty}[\mathrm{m} / \mathrm{s}]$ & 1.5 \\
\hline Potential temperature gradient, $d \theta / d z[\mathrm{~K} / \mathrm{m}]$ & 0.047 \\
\hline Obukhov stability parameter, $\zeta$ & 3.1 \\
\hline Gradient Richardson Number, $R i_{g}$ & 0.18 \\
\hline
\end{tabular}

\section{Results and Discussion}

Figure-4 shows the streamlines of the flow at horizontal plane (pedestrian level, $\mathrm{z}=10 \mathrm{~m}$ ) and vertical plane (middle of the building, $y=25 \mathrm{~m}$ ) in the three cases. As can be seen, the region behind the building witnesses large vortical structures that are supposed to enhance pollutant dispersion. One vortex develops near the roof and two develop near the two sides. Obviously, these are consequences of the flow separation at these edges. The development of vortices in the leeward side of the building has been pointed out by other authors [28]. For the $x-y$ plane view (Figures-4(a), (c) and (e)), as the spacing between buildings increases, the two vortices downstream the building expand. For the $\mathrm{x}-\mathrm{Z}$ view (Figures-4(b), (d) and (f)) the top vortex expands as well and totally detaches from the wall at $\lambda \mathrm{p}=15 \%$ (Figure-4(f)). Besides, a new vortex generates at the windward wall close to the ground.

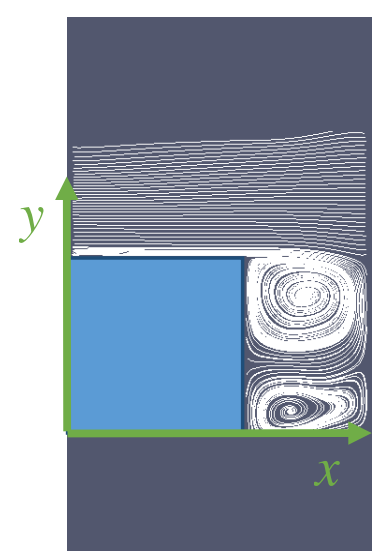

(a)

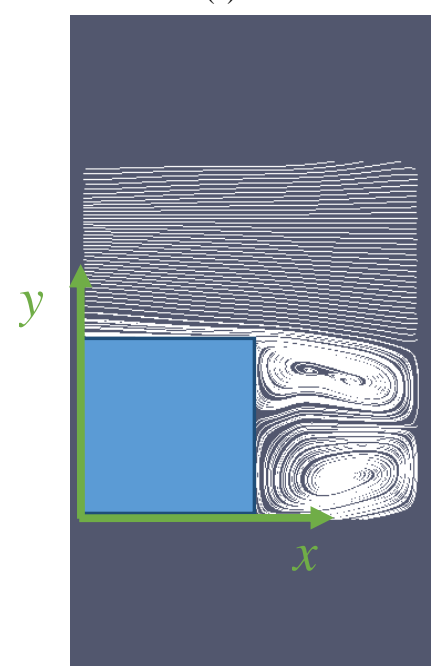

(c)
Figure-5 illustrates the effect of the flow structure on pollutant concentration coefficient for the different geometries under consideration. The left graphs ( $\mathrm{a}, \mathrm{c}$ and $\mathrm{e}$ ) represent color maps for a horizontal plane at the pedestrian level $(\mathrm{z}=10 \mathrm{~m})$ and right graphs $(\mathrm{b}, \mathrm{d}$ and $\mathrm{f})$ represent the high concentration $\left(F_{c} \geq 0.1\right)$ zones in the domain. It is clear from the color maps (Figure-5(a), (c) and (e)) that the enlarged cavity and expanded vortices in case of $\lambda p=25 \%$ and $\lambda p=15 \%$ participate to reducing the pollutant concentration (Figure-5(c) and (e)). However, the weakness of the vortices at low building densities $(\lambda p=15 \%)$ causes the pollutant to stuck close to the leeward wall. On the other hand, the clips of high pollutant concentration zones (Figure-5(b), (d), and (f)) demonstrate that for the same simulation time, the low building density allows dispersing pollutants to the furthest heights in the atmosphere and hence provides minimum concentrations at the ground level. It is worth mentioning that the strong dispersion of the pollutant in case of $\lambda p=25 \%$ and $\lambda p=15 \%$ (Figure-5(b), (d), and (f)) comes out from assigning the ground source a fixed concentration boundary condition. This implicates that as the atmosphere becomes more dispersive, the pollutant flow from source increases, gets spread in a wider space and less accumulation is encountered at all locations.

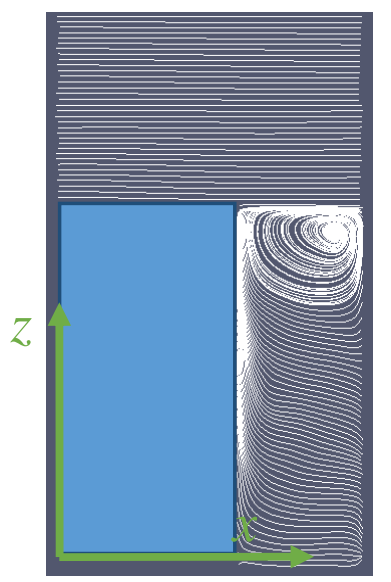

(b)

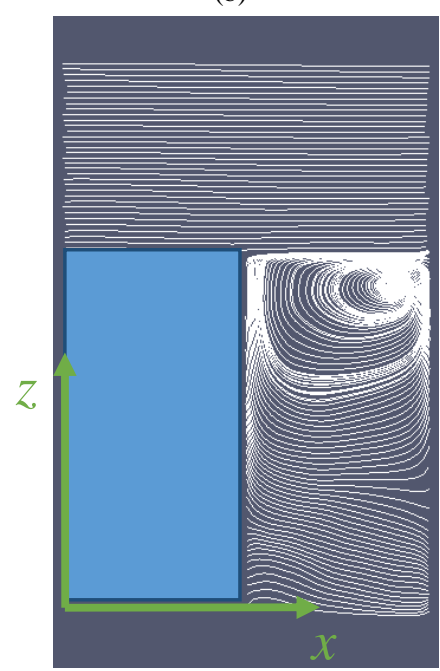

(d) 


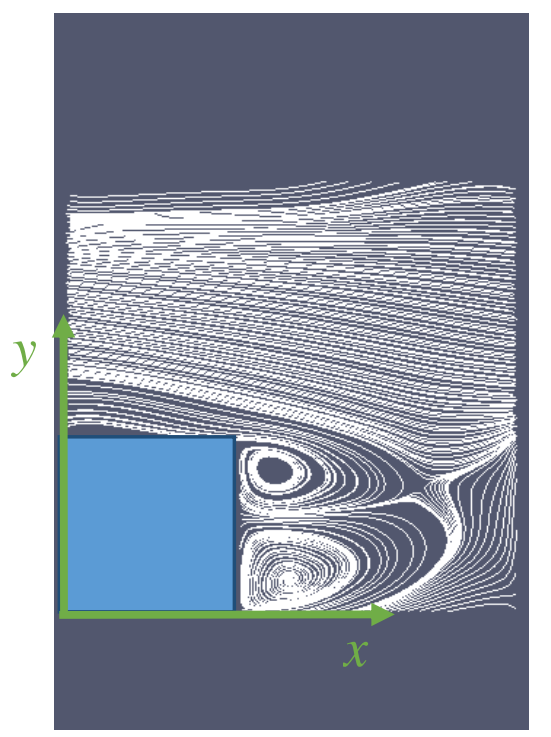

(e)

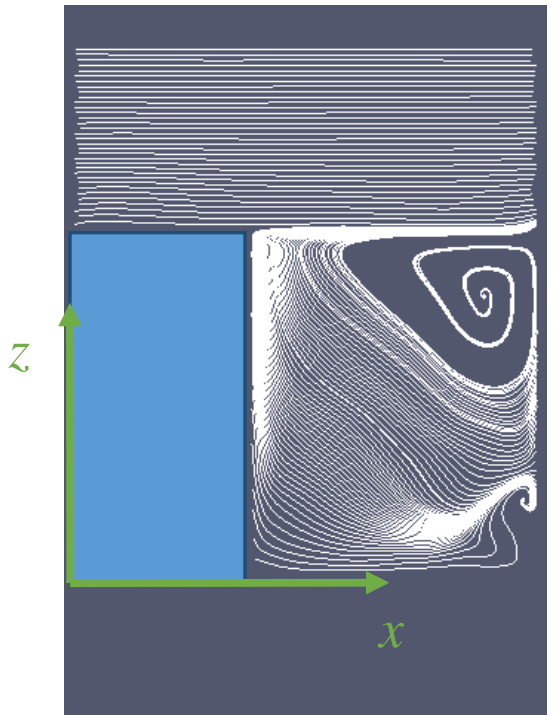

(f)

Figure-4. Streamlines through a horizontal section $(\mathrm{z}=10 \mathrm{~m}, \mathrm{a}, \mathrm{c}$ and e) and a vertical section $(\mathrm{y}=25 \mathrm{~m}, \mathrm{~b}, \mathrm{~d}$ and $\mathrm{f})$ for the three building arrangements; (a) and (b): $\lambda_{p}=35 \%$ (c) and (d): $\lambda_{p}=25 \%$ and (e) and (f): $\lambda_{p}=15 \%$. 


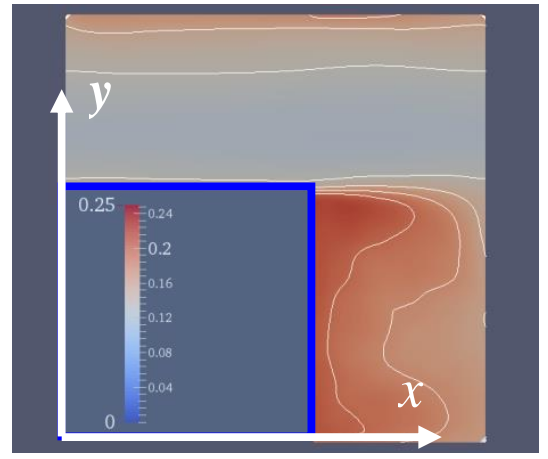

(a)

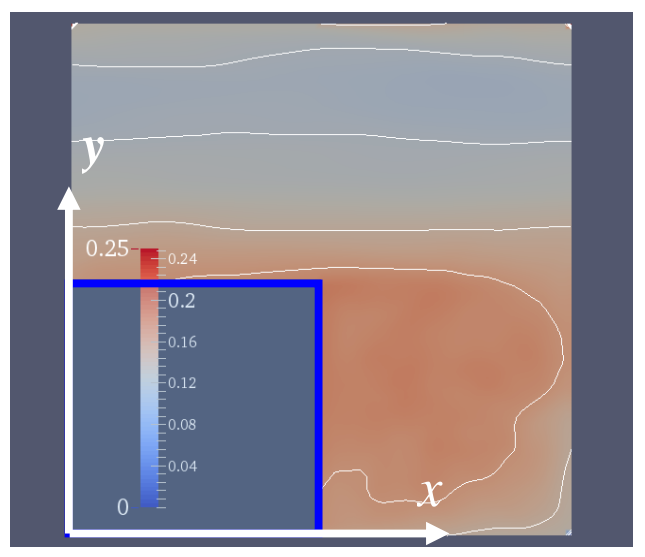

(c)

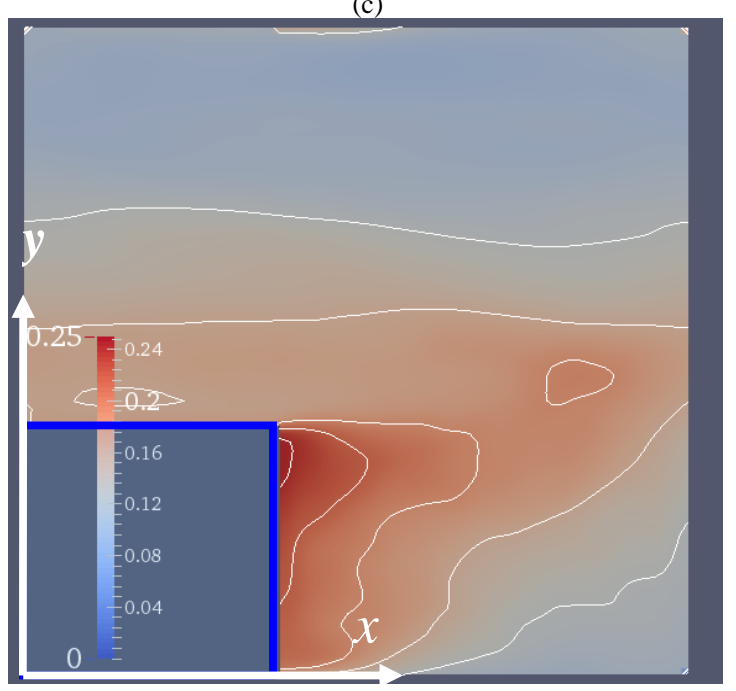

(e)

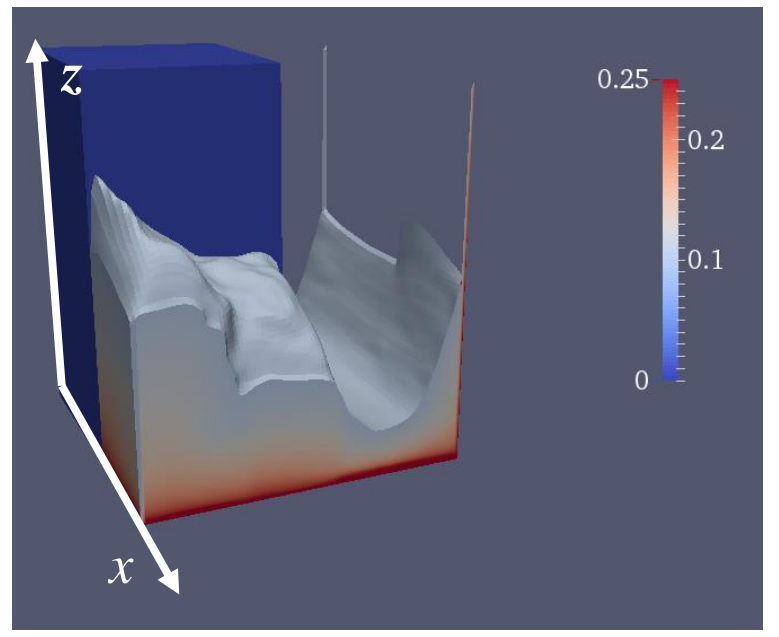

(b)

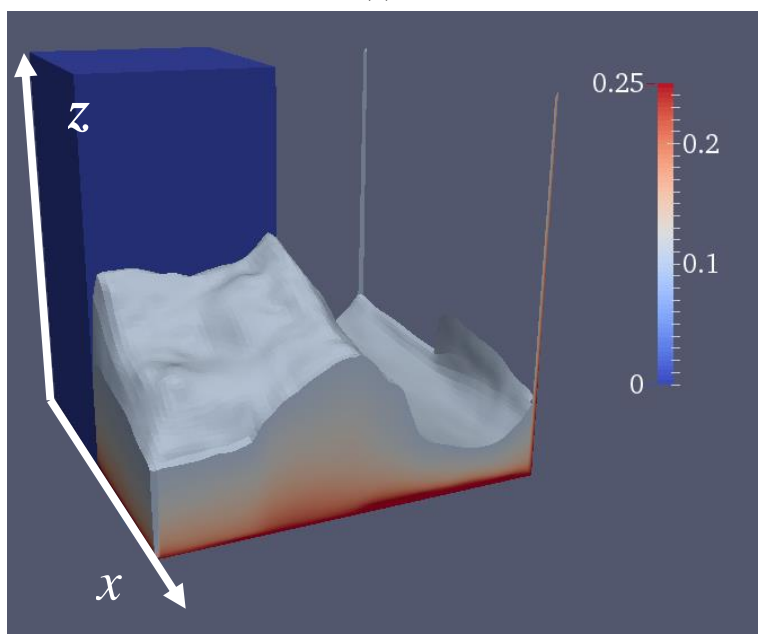

(d)

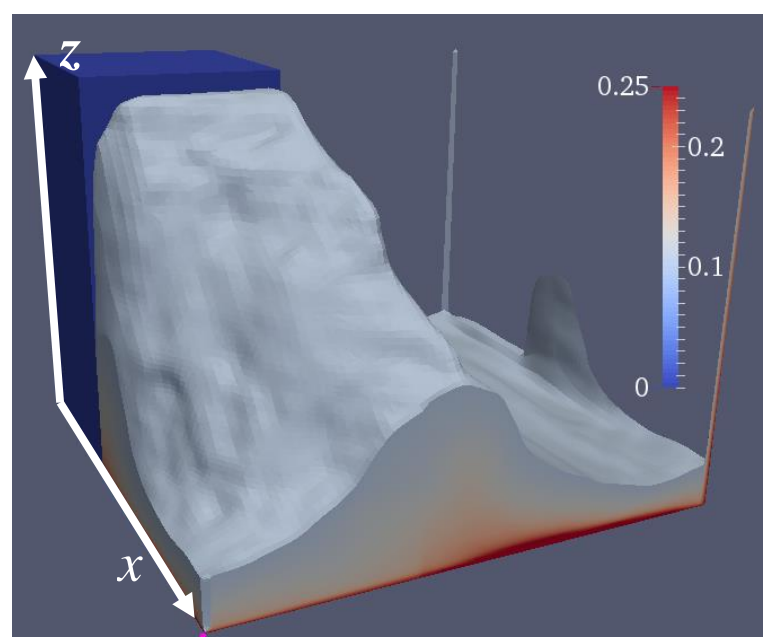

(f)

Figure-5. Color map of pollutant concentration coefficient $(\mathrm{z}=10 \mathrm{~m}$ plane, a, $\mathrm{c}$ and $\mathrm{e}$ ) and clips of high pollutant concentration regions $\left(F_{c} \geq 0.1, \mathrm{~b}, \mathrm{~d}\right.$ and f) for the three plane area densities; (a) and (b): $\lambda_{\mathrm{p}}=35 \%$ (c) and (d): $\lambda_{\mathrm{p}}=25 \%$ and (e) and (f): $\lambda_{\mathrm{p}}=15 \%$.

These conclusions are better visualized by Figure-6 which shows the concentration profiles along selected $\mathrm{y}$ and $\mathrm{z}$ axes (refer to Figure-7). The $\lambda p=15 \%$ case produces the lowest concentration at ground level $(\mathrm{z}<0.2 \mathrm{H})$ (Figures-7(c) and (e)). Nevertheless, it shows high concentrations along the leeward wall z-axis (Figure7(a)). This is, as mentioned before, owing to the detachment of the vortical structure from the wall. It can be inferred, hence, that buildings introduce roughness to the wind flow that enhances turbulence and dispersion. Therefore, reasonably packed urban environments can improve natural ventilation. The $\lambda p=35 \%$ case generates the highest concentrations at the ground level for all positions. Along the y-axes (Figures-7(b), (d) and (f)) the $\lambda p=$ $15 \%$ design, again, shows best results at this pedestrian level except at the leeward wall. The $\lambda p=35 \%$ design is generally the worst and $\lambda p=25 \%$ is in between. 


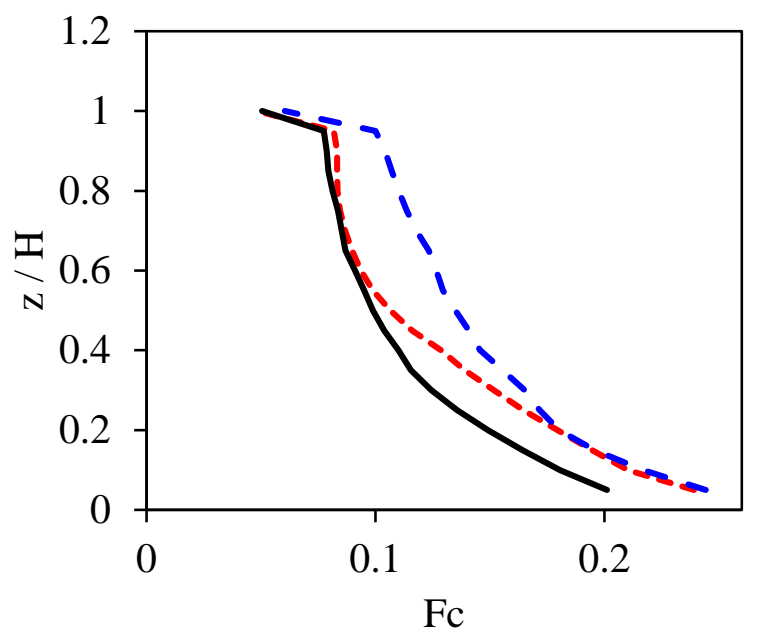

(a) $z_{1}$

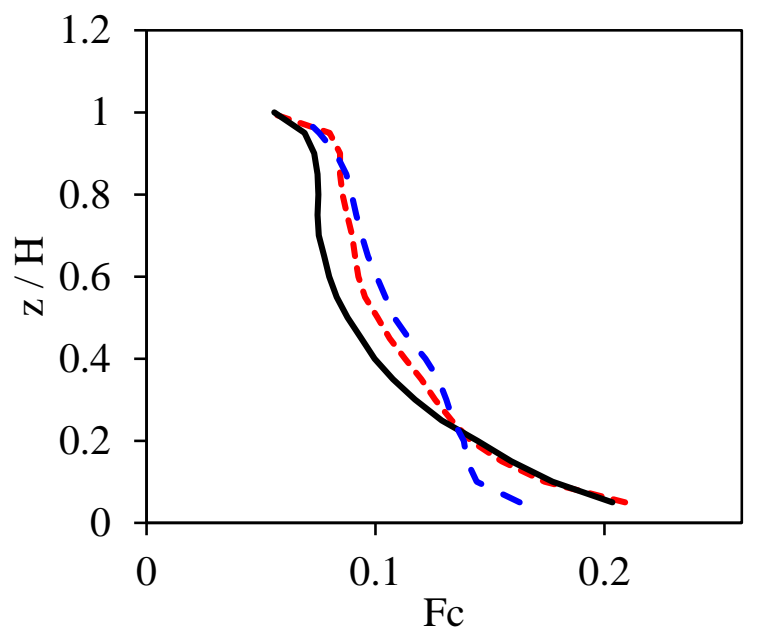

(c) $z_{2}$

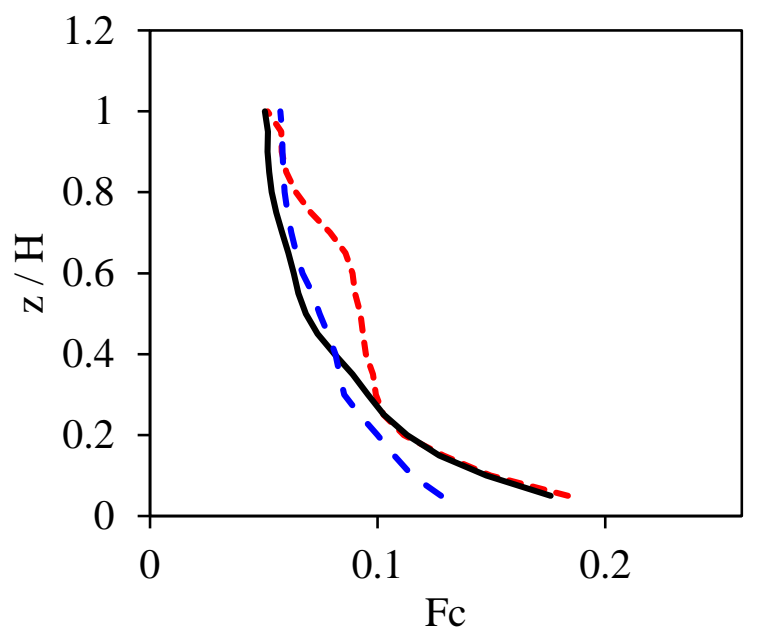

(e) $z_{3}$

Figure-6. Pollutant concentration along selected $y$ and $z$ axes (refer to Figure-7); dotted line $: \lambda_{\mathrm{p}}=35 \%$, solid line: $\lambda_{\mathrm{p}}=25 \%$ and dashed line: $\lambda_{\mathrm{p}}=$ $15 \%$.

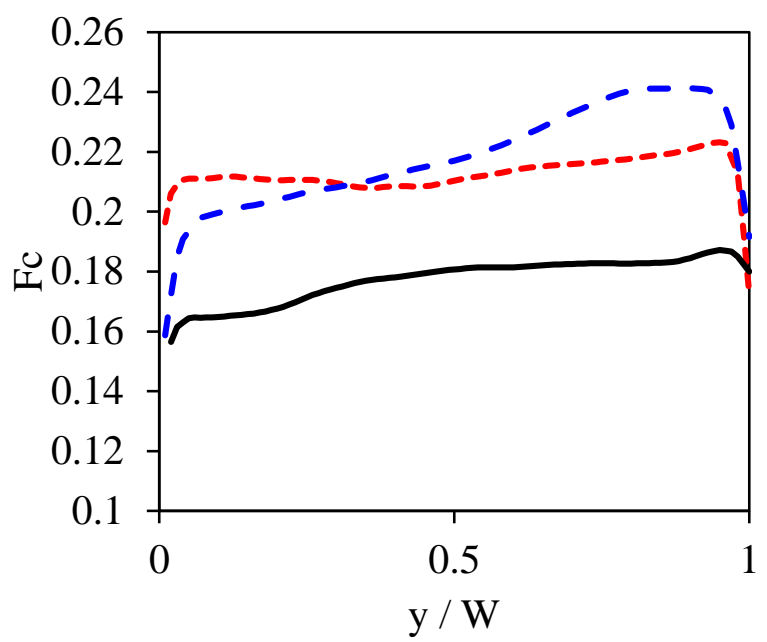

(b) $y_{1}$

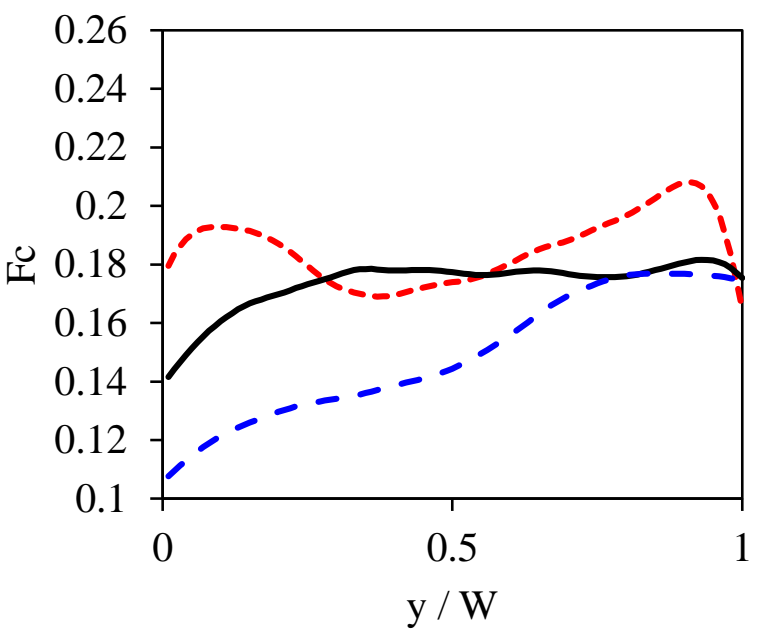

(d) $y_{2}$

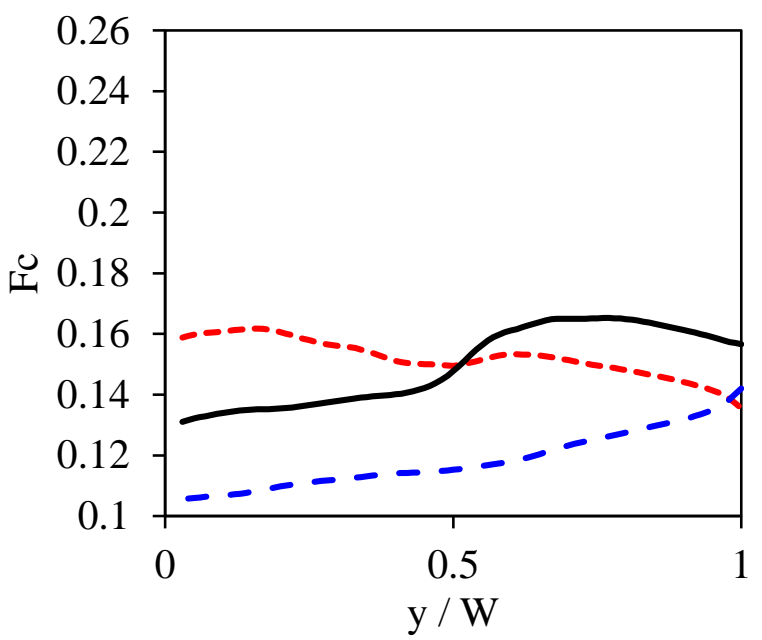

(f) $y_{3}$ 


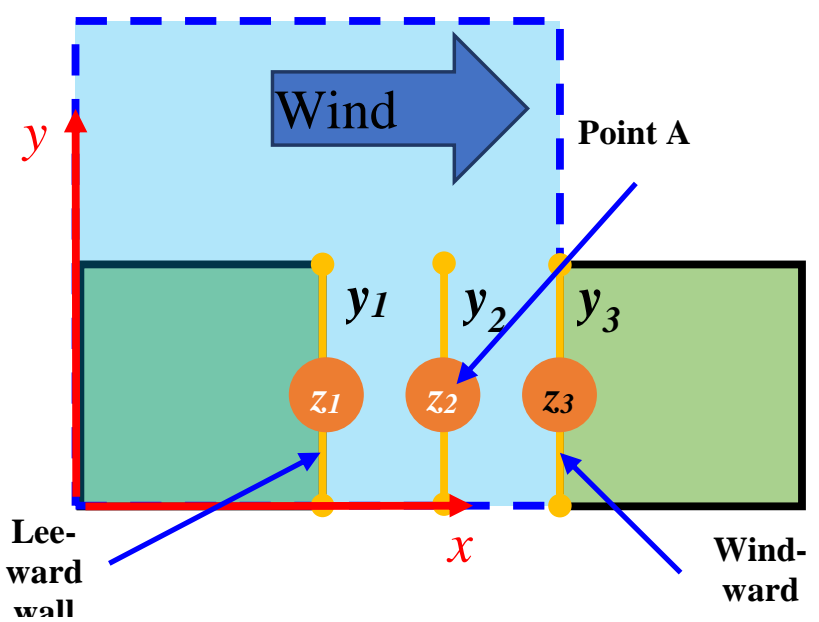

Figure-7. Axes and points utilized in the plots. All points and $y$-axes are located at $z=10 \mathrm{~m}$ height.

Finally, Figure- 8 tracks the time evolution of the concentration at point " $\mathrm{A}$ " in the middle distance between the two consequent buildings at a 10-m height, see Figure- 7 . The time is expressed in terms of the dimensionless time, $\tau$, defined here as:

$\tau=\frac{\text { Time } \times U_{\infty}}{H}$

Both the $\lambda p=35 \%$ and $\lambda p=15 \%$ geometries create high rates of increase at the first short period. This is because the former experiences small and far vortices and the latter experiences weak ones. However, after long time, the pollution in $\lambda p=15 \%$ maintains relatively lower values. The $\lambda p=25 \%$ case coincides with the $\lambda p=35 \%$ for most of the simulated time. This final state is illustrated by Figures-6(c) and (d).

Unfortunately, there are no experimental data in the literature to validate the current results. Thence, these were compared with [10] which examined the flow through a high-rise building model of aspect ratio $=2, \lambda p=25 \%$ and under neutral atmospheric condition. The comparison is shown in Figure-9. The figure shows the mean streamwise velocity at two $\mathrm{Z}$-axes, $\mathrm{S}$ and $\mathrm{V}$, refer to Figure-1. Although the similarity between the two trends, the stable atmosphere in the present research greatly dampens the wind velocity. This turns out from turbulence suppression by the stable boundary layer which restricts momentum transport between high and low speed layers and creates uneven windspeed profile.

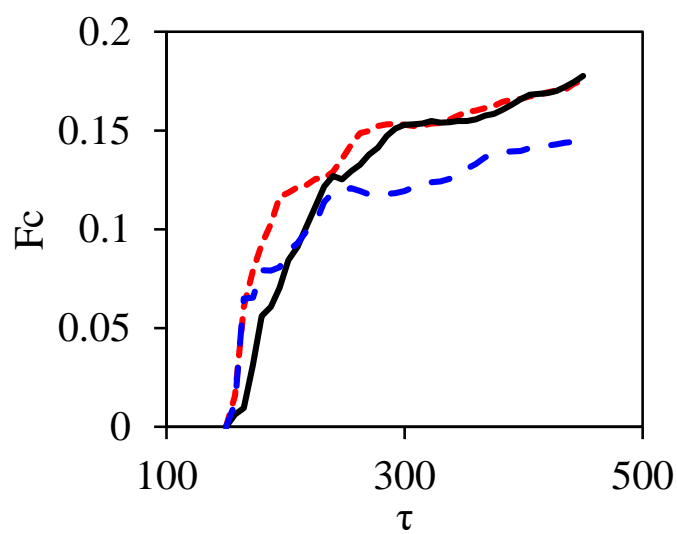

Figure-8. Comparing the time evolution of pollutant concentration for the three studied geometries at point "A"; dotted line: $\lambda_{\mathrm{p}}=35 \%$, solid line $: \lambda_{\mathrm{p}}$ $=25 \%$ and dashed line: $\lambda_{p}=15 \%$.

\section{Conclusions}

The pollutant dispersion in urban environment have been studied in this research for three plan area densities; $\lambda p=35,25$ and $15 \%$. The study focused on the deeply stable ABL as a worst dispersion condition. It was found that the vortical structure between the buildings is very narrow in case of $\lambda p=35 \%$. Meanwhile the model $\lambda p=15 \%$ exhibits large but detached vortices. It can be concluded then that high building densities trap pollutant in the cavities downstream buildings. While low densities, although allowing strong sweeping currents, witness weak vortical structures. Consequently, pollutants tend to pileup near the leeward wind wall of the building. An optimum building density between $15-25 \%$ is suggested. 


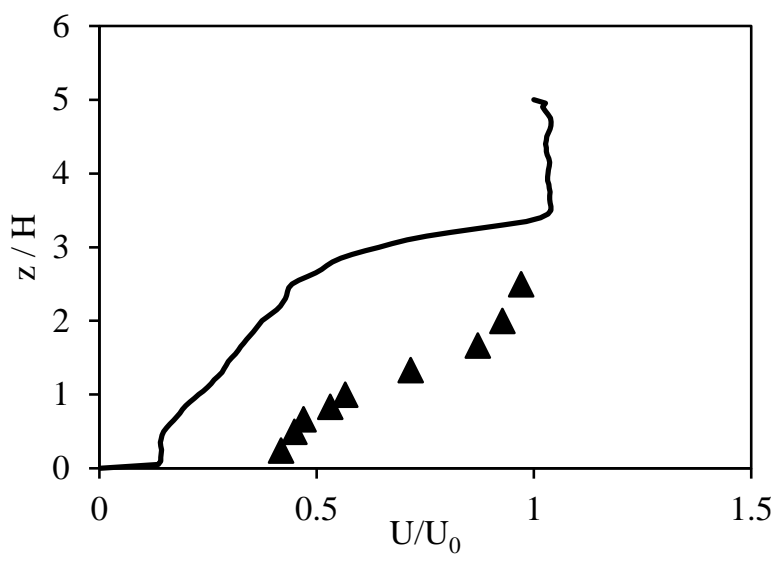

(a)

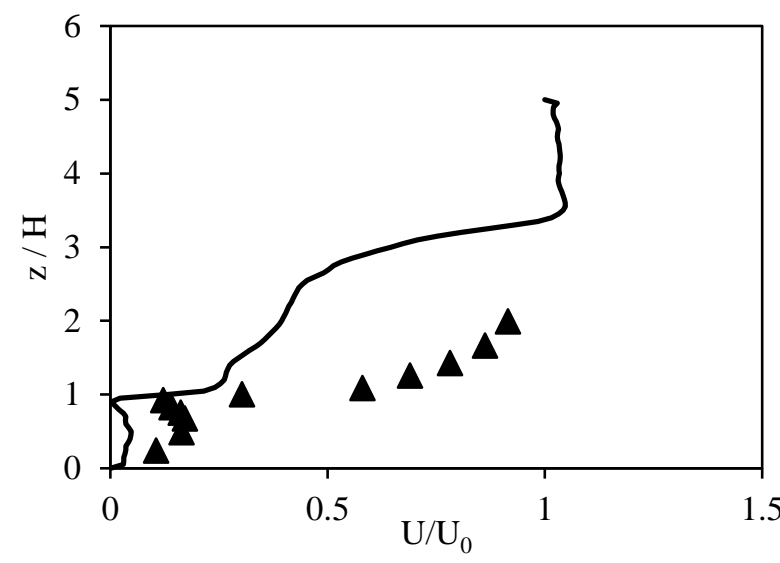

(b)

Figure-9. Streamwise velocity profiles for the $\lambda_{p}=25 \%$ model at points (a) $S$ and (b) V; the continuous line: the current data and $\mathbf{\Lambda}:$ [29].

\section{Acknowledgement}

The authors would like to thank Universiti Kebangsaan Malaysia for the Research University Grants (DIP-2015-006)) and the Ministry of Education for the Fundamental Research Grant (FRGS/1/2016/TK03/UKM/02/1)

\section{References}

[1] HEI, I. (2017) State of global air 2017: a special report on global exposure to air pollution and its disease burden

[2] Emeis, S. (2010), Surface-based remote sensing of the atmospheric boundary layer, 40 Springer Science \& Business Media

[3] Stull, R.B. (2012), An Introduction to Boundary Layer Meteorology, Springer Netherlands

[4] Boubel, R.W., Vallero, D., Fox, D.L., Turner, B. \& Stern, A.C. (2013), Fundamentals of Air Pollution, Elsevier

[5] Xie, Z.-T. \& Castro, I.P. (2009), Large-eddy simulation for flow and dispersion in urban streets. Atmospheric Environment 43, 2174-2185

[6] Gousseau, P., Blocken, B., Stathopoulos, T. \& Van Heijst, G.J.F. (2011), CFD simulation of near-field pollutant dispersion on a highresolution grid: a case study by LES and RANS for a building group in downtown Montreal. Atmospheric Environment 45, 428438

[7] Liu, Y.S., Cui, G.X., Wang, Z.S. \& Zhang, Z.S. (2011), Large eddy simulation of wind field and pollutant dispersion in downtown Macao. Atmospheric environment 45, 2849-2859

[8] Mavroidis, I., Andronopoulos, S. \& Bartzis, J.G. (2012), Computational simulation of the residence of air pollutants in the wake of a 3-dimensional cubical building. The effect of atmospheric stability. Atmospheric Environment 63, 189-202

[9] Cheng, W.C., Liu, C.-H. \& Leung, D.Y.C. (2009), On the comparison of the ventilation performance of street canyons of different aspect ratios and Richardson number. Building Simulation, 2, 53-61

[10] Hang, J., Li, Y., Sandberg, M., Buccolieri, R. \& Di Sabatino, S. (2012), The influence of building height variability on pollutant dispersion and pedestrian ventilation in idealized high-rise urban areas. Building and Environment 56, 346-360

[11] Tominaga, Y. \& Stathopoulos, T. (2013), CFD simulation of nearfield pollutant dispersion in the urban environment: A review of current modeling techniques. Atmospheric Environment 79, 716730

[12] Tominaga, Y. \& Stathopoulos, T. (2016), Ten questions concerning modeling of near-field pollutant dispersion in the built environment. Building and Environment 105, 390-402

[13] Salim, S.M., Buccolieri, R., Chan, A. \& Di Sabatino, S. (2011), Numerical simulation of atmospheric pollutant dispersion in an urban street canyon: comparison between RANS and LES. Journal of Wind Engineering and Industrial Aerodynamics 99, 103-113

[14] Kikumoto, H. \& Ooka, R. (2012), A numerical study of air pollutant dispersion with bimolecular chemical reactions in an urban street canyon using large-eddy simulation. Atmospheric environment $54,456-464$
[15] Kim, W.-W. \& Menon, S. (1995), A new dynamic one-equation subgrid-scale model for large eddy simulations. In 33rd Aerospace Sciences Meeting and Exhibit, pp. 356

[16] Flores, F., Garreaud, R. \& Muñoz, R.C. (2013), CFD simulations of turbulent buoyant atmospheric flows over complex geometry: solver development in OpenFOAM. Computers \& Fluids 82, 1-13

[17] Klein, M. (2005), An attempt to assess the quality of large eddy simulations in the context of implicit filtering. Flow, Turbulence and Combustion 75, 131-147

[18] Salim, S.M., Cheah, S.C. \& Chan, A. (2011), Numerical simulation of dispersion in urban street canyons with avenue-like tree plantings: comparison between RANS and LES. Building and Environment 46, 1735-1746

[19] Frank, J., Hellsten, A., Schlünzen, H. \& Carissimo, B. (2007), Best practice guideline for the CFD simulation of flows in the urban environment. Inthe COST Action 732. Quality Assurance and Improvement of Meteorological Models, University of Hamburg, Meteorological Institute, Center of Marine and Atmospheric Sciences

[20] Moonen, P., Dorer, V. \& Carmeliet, J. (2012), Effect of flow unsteadiness on the mean wind flow pattern in an idealized urban environment. Journal of Wind Engineering and Industrial Aerodynamics 104, 389-396

[21] Qu, Y., Milliez, M., Musson-Genon, L. \& Carissimo, B. (2012), Numerical study of the thermal effects of buildings on low-speed airflow taking into account 3D atmospheric radiation in urban canopy. Journal of Wind Engineering and Industrial Aerodynamics $104,474-483$

[22] Auger, L. \& Legras, B. (2007), Chemical segregation by heterogeneous emissions. Atmospheric Environment 41, 23032318

[23] Nozu, T., Tamura, T., Okuda, Y. \& Sanada, S. (2008), LES of the flow and building wall pressures in the center of Tokyo. Journal of Wind Engineering and Industrial Aerodynamics 96, 1762-1773

[24] Gu, Z.-L., Zhang, Y.-W., Cheng, Y. \& Lee, S.-C. (2011), Effect of uneven building layout on air flow and pollutant dispersion in nonuniform street canyons. Building and Environment 46, 2657-2665

[25] Sun, L., Nottrott, A. \& Kleissl, J. (2012), Effect of hilly urban morphology on dispersion in the urban boundary layer. Building and Environment 48, 195-205

[26] Harun, Z., Reda, E. \& Zulkifli, R. (2017), Buoyancy effect on atmospheric surface layer: measurements from the East Coast of Malaysia. In Journal of Physics: Conference Series, 822, pp. 12043

[27] Reda, E. \& Harun, Z. (2018), Effect of atmospheric boundary layer stability on the inclination angle of turbulence coherent structures, Environmental Fluid Mechanics 18 (3), 637-659

[28] Hang, J., Li, Y. \& Sandberg, M. (2011), Experimental and numerical studies of flows through and within high-rise building arrays and their link to ventilation strategy. Journal of Wind Engineering and Industrial Aerodynamics 99, 1036-1055 